\title{
SELF-SELECTION OF RETURN MIGRANTS IN BRAZIL AND INEQUALITY
}

\author{
Silvio H. T. TAI * \\ Ana Carolina B. M. Ribeiro ${ }^{\dagger}$
}

\begin{abstract}
Resumo
Esse artigo estuda a autosseleção dos emigrantes retornados no Brasil, de 2001 a 2010. Verificou-se empiricamente o impacto da desigualdade de renda na autosseleção através de dois canais opostos. Em primeiro lugar, os custos de migração impedem indivíduos com baixa qualificação de emigrar, o que contribui para a seleção positiva. Essa seleção é acentuada em locais com muita desigualdade. Em segundo lugar, indivíduos com baixa qualificação têm incentivos salariais para emigrar de estados mais desiguais, o que contribui para a seleção negativa. Considerando os dois canais, os efeitos dos custos de emigração são mais importantes, com predominância da seleção positiva.
\end{abstract}

Palavras-chave: Desigualdade, Emigrantes retornados, Autosseleção, Brasil.

\begin{abstract}
This paper investigates self-selection of returnees migrants in Brazil, from 2001 to 2010 . We find evidence of the impact of inequality on selfselection through two opposing channels. First, migrations costs prevent low-skilled individuals from emigrating, which support positive selection. This selection is accentuated in locations with high inequality. Secondly, we find that low-skilled individuals have wage incentives to emigrate from states with relative high inequality, implying a negative impact on selection. All in all, we find more important effects of migration costs, with the predominance of positive selection.
\end{abstract}

Keywords: Inequality, Return Migration, Self-selection, Brazil.

JEL classification: F22, J15, J24, J31

DOI: http://dx.doi .org/10.11606/1413-8050/ea 146640

\footnotetext{
${ }^{*}$ RITM - University Paris XI Sud, France and Pontifical Catholic University of Rio Grande do Sul, Brazil. E-mail: silviotai@gmail.com.

${ }^{\dagger}$ Ph.D. candidate at the Pontifical Catholic University of Rio Grande do Sul, Brazil. E-mail: carolbmribeiro@hotmail.com.
} 


\section{Introduction}

Several studies indicate that migration from developing to developed countries tend to be relatively qualified, in relation to the individuals in the origin country. This phenomena may be harmful and prevent developing countries from keeping human capital, a fundamental input of economic development (Mankiw et al. 1992) and an essential factor to devise and develop new technologies (Romer 1990). ${ }^{1}$

The recent crisis in developed countries, combined with stabilization and growth in Brazil, has progressively attracted not only foreign migrants, but also Brazilian returnees. ${ }^{2}$ The flows of Brazilian returnees had a three-fold increase from 2005 to $2010 .^{3}$ One could expect the return of human capital that "drained" in the past, as well as the return of labor. Considering immigration as an inflow of human capital, returnees have some advantages compared to foreign immigrants. Firstly, they do not face bureaucratic, cultural, or linguistic barriers in migrating back to Brazil. Secondly, their return migration does not trigger, at first, negative attitudes in compatriots that remained in Brazil. ${ }^{4}$

Returnees are considered in this paper because they are paid at the same prices of other Brazilians, allowing a direct comparison. We find evidence that these migrants have more education and earn higher wages than Brazilians who remained in the country. Since Brazil is one of the most unequal countries worldwide, one would expect the opposite, that highly educated Brazilians would remain in the country. Considering that they earn relative high salaries, why do these individuals tend to migrate to other countries (and return some time later)?

This article quantifies the self-selection of return migrants in Brazil from 2001 to 2010, and estimates the impact of the underlying theoretical mechanisms of selection through inequality. Using microdata from the 2010 census, this paper compares wages of native-returnees to those of non-migrant natives in each Brazilian state, providing a direct wage comparison. The role of inequality on the correlation between education and migration costs is a key issue in our study.

We found evidence of the impact of inequality on self-selection through two opposing channels. On one hand, migration costs prevent low-skilled individuals from migrating, which supports positive selection. This selection is more elevated in Brazilian states with high inequality, because they present high return to skills. On the other hand, low-skilled individuals have incentives for migrating to countries with low inequality where, their wage is higher, which supports negative selection. Both channels are empirically verified, with a predominance of the former.

Borjas (1987) shows that migration from countries with relatively high inequality and high rates of return to schooling is negatively selected. This theoretical implication is based on a simplified assumption: migration costs are a constant proportion of individuals' income, regardless of their educa-

\footnotetext{
${ }^{1}$ Nonetheless, recent studies point to positive network externalities. See Docquier \& Rapoport (2012) for a survey.

${ }^{2}$ Between 2001 and 2010, the inflow of returnees was 2.5 higher than the inflow of foreigners.

${ }^{3}$ See Figure 2.

${ }^{4}$ A stream of the literature (Facchini \& Mayda 2009, Müller \& Tai 2016) indicates that natives can have negative opinions regarding immigration, either because they can represent a competition in the labor market or because foreigners impose a net cost on the redistribution system.
} 
tion level or wage. Without this hypothesis, migration costs would represent larger proportions of low-skilled individuals' wage, reducing their motivations to migrate (Chiswick 1999, Assunção \& Carvalho 2013).

Chiquiar \& Hanson (2005) consider variable time-equivalent costs correlated with skills to be what theoretically underpins negative, intermediate and positive selection, depending on the amount of costs and their correlation with skills. Empirically, they find intermediate selection as they compare wage densities of Mexican residents to counterfactual constructed wage densities that would be obtained were Mexican immigrants in the US paid accordingly to Mexican prices. This paper presents the advantage of direct wage comparisons (without price heterogeneity) and also the possibility of econometric examination of different theoretical arguments determining selection, notably the implication of variable proportional costs on the liquidity constraint. Although Chiquiar \& Hanson (2005) justify intermediate selection via variable time-equivalent costs, they did not empirically test this hypothesis.

Belot \& Hatton (2012) estimate the self-selection determinants for OECD's immigrants. They focus on the poverty constraint and propose that less educated individuals have higher time-equivalent migration costs if their source country is poor. This approach is close to that applied to the second-step regressions in this paper. Although our empirical results are similar, there is a fundamental difference: we use inequality instead of poverty. The theoretical model indicates that inequality determines selection, not poverty.

For instance, one can consider a very poor country where everybody is poor. In this case, the poorest individuals cannot migrate, but selection is not observed because richer individuals cannot migrate either. A country may be poor or rich, but if the correlation between time-equivalent costs and skills is low (otherwise stated, if the inequality is low), cost-based positive selection is low.

In addition, differently from Belot \& Hatton (2012), this paper makes use of individual data, which allows us to investigate self-selection on observed and unobserved characteristics by education level.

Borjas \& Bratsberg (1996) extend Borjas (1987) return migration model, arguing that there is a negative selection in the migration and a positive selection in the return migration. ${ }^{5}$ It is important to note that the selection in (the first) migration compares migrants to native non-migrants whereas the selection in the return (second) migration compares migrants that are coming back to those that remained in the destination country.

This paper compares returnee migrants to natives that have never migrated. In the context of Borjas and Bratsberg's model (with constant timeequivalent costs), only the "first" selection counts, in this case returnees migrants would be negatively selected. Once again, variable time-equivalent costs would change these implications. ${ }^{6}$

\footnotetext{
${ }^{5}$ As migration to countries with relatively low return to skills is negatively selected, the first individuals to migrate are those with the lowest skills (alternatively, individuals with the lowest skill are those with the highest incentives to migrate). Eventually, a certain stock of immigrants lives in the foreign country. When these immigrants decide to go back to their source country, the move starts with the most skilled within the settled immigrants' stock, or the latest to arrive (alternatively, those persons that migrate from source to destination country, but with the lowest incentives.)

${ }^{6}$ Education obtained in a foreigner country can not be controlled and may bias the results.
} 
The main contribution of this paper is to clarify migration self-selection mechanisms based on migration costs and inequality. It is evident that the brain drain caused by positive selection in unequal countries like Brazil, frequently found in the literature, is largely explained by migration costs and high levels of inequality.

The remainder of this paper is divided into five sections. Section 2 sketches Borjas (1987) model and includes variable time-equivalent migration costs. Section 3 presents the econometric specification. Section 4 details individual data of return migration in Brazil from 2001 to 2010. Section 5 analyzes the results of the empirical analysis, and finally section 6 presents our conclusions.

\section{Theory}

\subsection{Self-selection}

Borjas (1987), based on Roy's 1951 model, shows that migrants from countries with relatively high returns to skills and also high earning inequality are negatively selected. A strong hypothesis for this result is that time-equivalent migration costs are constants across all individuals. Therefore, low-skilled individuals living in countries with high returns to skills tend to migrate to more equalitarian countries where low-skilled individuals are not so penalized with relative low wages.

Nevertheless, if time-equivalent migration costs are higher for low-skilled individuals, those costs represent an obstacle for them. Chiquiar \& Hanson (2005) consider a negative correlation between time-equivalent costs and skills, ${ }^{7}$ which underpins the intermediate selection for migrants from Mexico to the US that they found.

Self-selection occurs twice in return migration; when the individual migrates from home country to foreign country, and when she or he migrates back. Borjas \& Bratsberg (1996) indicates that if there is positive selection in the first migration, there will be negative selection in the second migration. Nevertheless, if one compares returned migrants with native non-immigrant individuals, what determines their differences is the first selection. This article compares wages of Brazilian returned migrants with those native nonimmigrant individuals. This comparison is driven by the first selection, despite the second selection. ${ }^{8}$

Figure 1 illustrates the self-selection on return migration. Considering the "first" migration positively selected, the "second", or return migration, would be negatively selected. However, the latter, those individuals that "migrate temporarily" are on average more educated than those individuals that "stay in the source country".

Following Borjas (1987), Borjas \& Bronars (1991), Borjas \& Bratsberg (1996), wages $w$ in Brazilian states $i$ are distributed according to the mean log of

\footnotetext{
${ }^{7}$ See Chiquiar \& Hanson (2005, pp. 243) for examples justifying negative correlation between time-equivalent costs and skills.

${ }^{8}$ For instance, if the first selection is positive, individuals in the foreign country are more educated than those natives that remained in the home country. Immigrant that return, are in average more educated than non-migrant natives, even if they among the least educated among those migrants in the foreign country (even if the second selection is negative.
} 


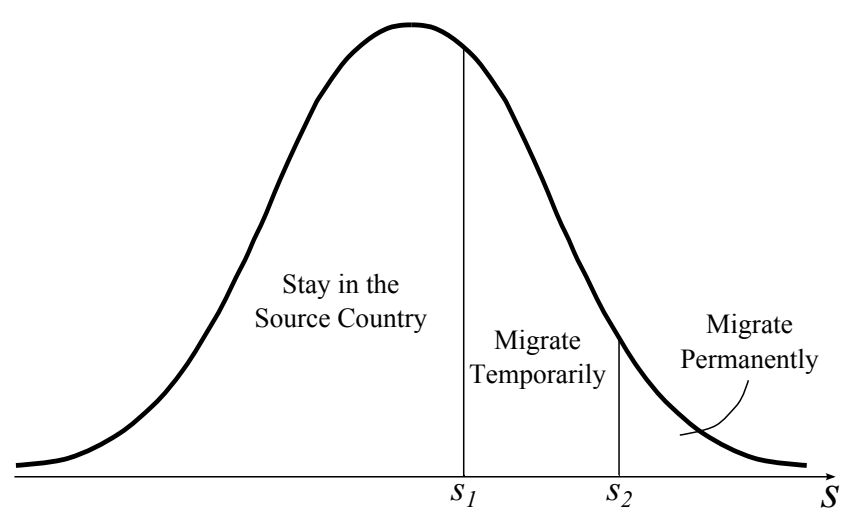

Figure 1: Self-Selection of Return Migration

wages in each state $\mu_{i}$, the return to skills $\sigma_{i}$ and according to the individual skill $S$ :

$$
\ln \left(w_{i}\right)=\mu_{i}+\sigma_{i} S
$$

If the population of the source location $i$ (henceforth Brazilian state, for the sake of clarity) migrated to destination country $j$, they would face the following distribution of wages:

$$
\ln \left(w_{j}\right)=\mu_{j}+\sigma_{j} S
$$

Considering time-equivalent migrations costs $C_{i j},{ }^{9}$ an individual migrates from state $i$ to country $j$ if migration index $I$ is positive:

$$
I=\mu_{j}+\sigma_{j} S-\mu_{i}-\sigma_{i} S-C_{i j}
$$

Self-selection is then determined by its partial derivative on skills:

$$
\frac{\partial I_{i j}}{\partial S}=\sigma_{j}-\sigma_{i}-\frac{\partial C_{i j}}{\partial S}
$$

Borjas (1987) assumes that time-equivalent migration costs are constant for all individuals, which eliminates the last term of equation (4). Chiquiar \& Hanson (2005) defend a more realistic view where these costs are constant in "financial terms", but time-equivalent costs vary according to the individual income.

This hypothesis, on one hand, accentuates positive selection since migration costs represent a higher proportion of income (thus, a higher migration' barrier) for least-skilled individuals. Even when the differential of return to skill imposes a negative selection, migration costs are more severe for the leastskilled people, preventing them from migrating.

On the other hand, if one considers variable time-equivalent costs, heterogeneity in returns to skill has to be taken into account. The higher the return to education, the higher the negative correlation between migration costs and

\footnotetext{
${ }^{9}$ Considering $F_{i j}$ as total migration costs, we considered that $\ln \left(w_{i}+F_{i j}\right) \approx \ln \left(w_{i}\right)+C_{i j}$, where $C_{i j}$ are time-equivalent costs.
} 
skills, thus, leading to even more positive selection. Time-equivalent costs of migration is a function of: ${ }^{10}$

$$
C_{i j}=f\left(F_{i j}, S, \sigma_{i}\right)
$$

Instead of assuming or imposing very specific functional forms for timeequivalent migration costs, ${ }^{11}$ we would rather have skills $S$ interact with financial costs $F_{i j}$. Considering equation (6), if $\beta_{3}$ is negative, migration costs are the highest for those individuals with no education at all, and they progressively decrease according to the skill level. ${ }^{12}$

$$
C_{i j}=\beta_{0}+\beta_{1} S+\beta_{2} F_{i j}+\beta_{3} F_{i j} S
$$

This specification assumes that time-equivalent migration costs decrease with skills in the same way everywhere. However, these costs may decrease differently according to the return to skills within each location. Specification (7) takes into account that migration costs represent different proportions of a given individual's income, according to the location's return to skills $\left(\sigma_{i}\right) .{ }^{13}$

$$
C_{i j}=\beta_{0}+\beta_{1} S+\beta_{2} F_{i j}+\beta_{3} F_{i j} S+\beta_{4} \sigma_{i} F_{i j} S
$$

The partial derivative of equation (7) on skills leads to:

$$
\frac{\partial C_{i j}}{\partial S}=\beta_{1}+\beta_{3} F_{i j}+\beta_{4} \sigma_{i} F_{i j}
$$

We expect that time-equivalent costs decreases with skills, therefore: $\beta_{1}+$ $\beta_{3} F_{i j}+\beta_{4} \sigma_{i} F_{i j}<0$ and that they decrease even more if the return to skills is higher, then: $\beta_{4}<0$.

The coefficient $\beta_{1}$ captures the effect of migration costs that are constant for any pair of state-country, we expect $\beta_{1}<0$.

Replacing equation (8) in equation (4) leads to:

$$
\frac{\partial I_{i j}}{\partial S}=\sigma_{j}-\sigma_{i}-\beta_{1}-\beta_{3} F_{i j}-\beta_{4} \sigma_{i} F_{i j}
$$

Borjas (1987) considers only the $\sigma_{j}-\sigma_{i}$ difference to explain the self-selection of migrants. In the case of an unequal country such as Brazil, this difference is predominantly negative and implies negative selection of Brazilian emigrants. Where time-equivalent costs of migration is a function of skills and return to skills, the selection equation would include other terms $\left(-\beta_{1}-\beta_{3} F_{i j}-\beta_{4} \sigma_{i} F_{i j}\right)$. One can notice that even if the $\sigma_{j}-\sigma_{i}$ difference has a negative impact on selection, the other terms have a positive effect on self-selection. The econometric analysis shows that the latter prevails.

\footnotetext{
${ }^{10}$ Rate of return to skill in source locations is considered, as migration costs are incurred before the migration itself.

${ }^{11}$ E.g. Chiquiar \& Hanson (2005, pp.243) consider the following form for time-equivalent migration costs (noted as $\pi$ ): $\pi=\exp \left(\mu_{p}-\delta_{p} S\right)$, where $\mu_{p}$ and $\delta_{p}$ are constants.

${ }^{12}$ Interaction terms with higher order for skills " $S$ " were tested and are readily available under request. Nevertheless, they do not present significant effects.

${ }^{13}$ The rate of return to skills is interacted only with the interaction between Financial Costs and Skills (coefficient $\beta_{4}$ ). Other terms do not depend on this rate, for instance $\beta_{3}$ quantifies the effect of Financial Costs on Time-Equivalent costs for null skill level. In this case, it is meaningless to consider the rate of return to skills, since skills are equal to zero.
} 
The inequality of origin location $\sigma_{i}$ has two opposite impacts on self-selection. Firstly, in line with Borjas, the impact is negative since it is equivalent to a high return to education rate in the origin place (preventing highly educated people from migrating). Secondly, it impacts self-selection positively because high levels of inequality raise the correlation between time-equivalent costs of migration and education. In the extreme case with very high levels of inequality, time-equivalent costs are huge for low educated people (preventing them from migrating) and tiny for highly educated people. The two opposing impacts of the inequality of origin location on selection is given by equation (10), as $\beta_{4}<0$.

$$
\frac{\partial^{2} I_{i j}}{\partial S \partial \sigma_{i}}=-1-\beta_{4} F_{i j}
$$

Therefore, Borjas' specification would be affected by a missing variable bias. In particular, if the magnitude of $\beta_{4}$ is large enough, the biased coefficient of the $\sigma_{j}-\sigma_{i}$ difference would be even positive. This bias is indeed verified in the econometric analysis.

\section{Econometric Specification}

\subsection{Estimations of Self-Selection - First-Step Regressions}

We followed Borjas \& Bratsberg (1996) methodology. The term of selection $\frac{\partial I_{i j}}{\partial S}$ is defined for each Brazilian state $i$ as the average log wage difference between migrants from country $j$ (Brazilian states' natives that have already migrated to country $j$ and then returned to state $i$ ) and non-migrants (natives in state $i$ that have never migrated). Thus, a first-step regression is thus estimated for each Brazilian state $i:{ }^{14}$

$$
\ln \left(w_{i}^{k}\right)=\sum_{j}^{n} \delta_{i j} D_{i j}^{k}+\zeta_{i} \mathbf{X}_{i}^{k}
$$

where $D_{i j}$ is a dummy indicating if individual $k$ is a migrant returned from country $j$ to Brazilian state $i$. The coefficient $\delta_{i j}$ gives, therefore, the migrant's $\log$ wage relative to natives. A vector of demographic controls $\mathbf{X}_{i}^{k 15}$ is included for the regressions of adjusted wages.

These first-step regressions are estimated for two cohorts: the first one for those migrants that returned between 2001 and 2005, and the second one for those migrants that returned between 2006 and 2010. This procedure controls for wages' differences related to the time of migration. Returnees that migrated before 2005 had more time to reintegrate to their homeland than those that migrated after 2005. Moreover, Brazil's economical situation changed over this period, ${ }^{16}$ and so did migration flows.

\footnotetext{
${ }^{14}$ Index $i$ is not meaningful in regressions represented by equation (11), as they are run for each state $i$; however, they are used because coefficients $\delta_{i j}$ are going to be pooled from each regression, in the second step.

${ }^{15}$ The controls are age, age squared, education level, marital status, health and metropolitan residence.

${ }^{16}$ In average, the Brazilian GDP grew from $2.80 \%$ in the first period to $4.49 \%$ in the second period. Source: World Bank Development Indicators.
} 
Figure 2 shows the evolution of these flows between 2001 and 2010. The average over the first period from 2001 to 2005 is about 7000 returnees while the average over the second period is about 24000 returnees. According to Borjas (1996, pp.173), larger amounts of migrants lead to a "more diluted quality of the typical immigrant in a flow that is positively selected". ${ }^{17}$ Therefore, selection is sharper in the first period than that in the second period, increasing wage heterogeneity.

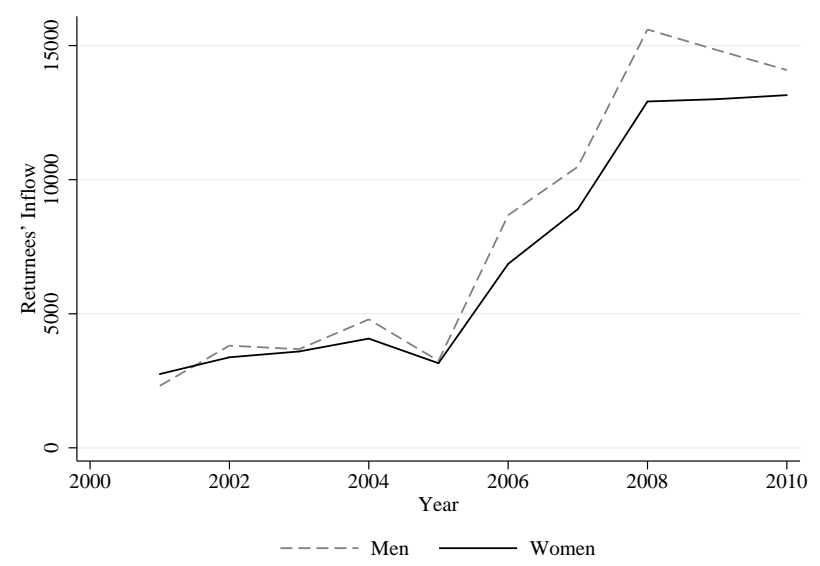

This figure considers 24-64 year-old individuals that were born is the state where they answered the 2010 Brazilian census. The total is 153298 individuals.

Figure 2: Inflows of Returnees by Year

\subsection{Proxies of Migration Costs and Return to Schooling}

Migration costs are represented by three different variables: the distance between the Brazilian state and the country of migration (for diminishing marginal effects, distance is also considered squared), common language, and contiguity, which are dummy variables that equal to one if the Portuguese is spoken in the country of migration, and if this country shares a border with the Brazilian state, respectively.

$$
F_{i j}=\lambda_{1} \text { Distance }_{i j}+\lambda_{2} \text { Distance }_{i j}^{2}+\lambda_{3} \text { Language }+\lambda_{4} \text { Contiguity }
$$

We expect that these costs are an increase function of distance: $\lambda_{1}>0$, $\lambda_{2}<0$, and that it decreases with common language and contiguity: $\lambda_{3}<0$ and $\lambda_{4}<0$

We followed Borjas \& Bratsberg (1996) and proxy for the rates of return to skills using a measure of income inequality, the (quintile) ratio, henceforth $q:^{18}$

\footnotetext{
${ }^{17}$ Recalling that Borjas (1996) does not consider variable time-equivalent costs and then positive selection is due only to differences in the rates of return to skill.

${ }^{18}$ We use the ratio of the average income of the $20 \%$ richest individuals over the average income of the $20 \%$ poorest individual. Doing so, this ratio is consistent with data used for the inequality of migration countries, from UNDP (2011).
} 


$$
q_{i}=\theta \sigma_{i}
$$

\subsection{Determinants of Self-Selection - Second Step Estimable Equations}

The estimable equation of (9) is:

$$
\begin{aligned}
\delta_{i j}=\alpha_{0}+\alpha_{1}\left(q_{j}-q_{i}\right) & +\alpha_{2} \text { Dist }_{i j}+\alpha_{3} \text { Dist }_{i j}^{2}+\alpha_{4} \operatorname{Lang}_{i j}+\alpha_{5} \text { Cont }_{i j} \\
+ & \alpha_{6} \text { Dist }_{i j} \sigma_{i}+\alpha_{7} \operatorname{Dist}_{i j}^{2} \sigma_{i}+\alpha_{8} \operatorname{Lang}_{i j} \sigma_{i}+\alpha_{9} \text { Cont }_{i j} \sigma_{i}
\end{aligned}
$$

Where: $\alpha_{0}=-\beta_{1}$

$$
\alpha_{0}=-\beta_{1}
$$

The model predicts $\alpha_{0}>0$

$$
\begin{gathered}
\alpha_{1}=\theta \\
\alpha_{1}>0 \\
\alpha_{2}=-\beta_{3} \lambda_{1} \text { and } \alpha_{6}=-\beta_{4} \lambda_{1}>
\end{gathered}
$$

The model predicts $\alpha_{2}$ Dist $_{i j}+\alpha_{6}$ Dist $_{i j} \sigma_{i}>0$ and $\alpha_{6}>0$

$$
\alpha_{3}=-\beta_{3} \lambda_{2} \text { and } \alpha_{7}=-\beta_{4} \lambda_{2}
$$

The model predicts $\alpha_{3}$ Dist $_{i j}^{2}+\alpha_{7}$ Dist $_{i j}^{2} \sigma_{i}<0$ and $\alpha_{7}<0$

$$
\alpha_{4}=-\beta_{3} \lambda_{3} \text { and } \alpha_{8}=-\beta_{4} \lambda_{3}
$$

The model predicts $\alpha_{4} \operatorname{Lang}_{i j}+\alpha_{8} \operatorname{Lang}_{i j} \sigma_{i}<0$ and $\alpha_{8}<0$

$$
\alpha_{5}=-\beta_{3} \lambda_{4} \text { and } \alpha_{9}=-\beta_{4} \lambda_{4}
$$

The model predicts $\alpha_{5}$ Cont $_{i j}+\alpha_{9}$ Cont $_{i j} \sigma_{i}<0$ and $\alpha_{9}<0$

The two opposing effects of the inequality of origin location on selection given by equation 10 are estimated by equation (15) below. Besides the role of inequality per se, given by $-\alpha_{1}$, one can notice that its interaction with factors that reduce migration costs have a positive impact on self-selection, as $\alpha_{8}$ and $\alpha_{9}$ are expected to be negative. Conversely, the interaction of inequality with the factor that raises migration costs has a positive impact on self-selection, as $\alpha_{6}$ Dist $_{i j}+\alpha_{7}$ Dist $_{i j}^{2}$ is expected to be positive

$$
-\alpha_{1}+\alpha_{6} \text { Dist }_{i j}+\alpha_{7} \text { Dist }_{i j}^{2}+\alpha_{8} \operatorname{Lang}_{i j}+\alpha_{9} \text { Cont }_{i j}
$$




\section{Data}

The Brazilian 2010 census counted 204,374 returnees that came back to Brazil from 2001 to 2010. In this study, we considered only individuals that returned to the state where they were born, ${ }^{19}$ doing so prevents counting people that are not returning, but migrating again. For example, we do not count as a returnee the individual that migrated from Bahia to the US and then migrated again to São Paulo. The self-selection of this individual is related to individuals in Bahia, not in São Paulo. As regressions are estimated by Brazilian states, we compared only individuals born within each state. Table 1 details these individuals by country of migration.

Table 1: Migration Country of Returnee Migrants

\begin{tabular}{lrrlrr}
\hline Country & Returnees & Perc. & Country & Returnees & Perc. \\
\hline Africa & 1870 & $1.22 \%$ & Asia & 29369 & $19.16 \%$ \\
Angola & 1077 & $0.70 \%$ & Japan & 27179 & $17.73 \%$ \\
Mozambique & 167 & $0.11 \%$ & China & 570 & $0.37 \%$ \\
Namibia & 102 & $0.07 \%$ & Un. Arab Emirates & 280 & $0.18 \%$ \\
Guinea-Bissau & 92 & $0.06 \%$ & Lebanon & 271 & $0.18 \%$ \\
Equatorial Guinea & 79 & $0.05 \%$ & Israel & 233 & $0.15 \%$ \\
Others & 353 & $0.23 \%$ & Others & 836 & $0.55 \%$ \\
& & & & & \\
America & 58739 & $38.32 \%$ & Europe & 58922 & $38.44 \%$ \\
United States & 36058 & $23.52 \%$ & Portugal & 14617 & $9.54 \%$ \\
Paraguay & 7561 & $4.93 \%$ & United Kingdom & 11579 & $7.55 \%$ \\
Bolivia & 3095 & $2.02 \%$ & Spain & 9817 & $6.40 \%$ \\
Argentina & 2947 & $1.92 \%$ & Italy & 8056 & $5.26 \%$ \\
Canada & 2378 & $1.55 \%$ & France & 4278 & $2.79 \%$ \\
Uruguay & 1273 & $0.83 \%$ & Germany & 3434 & $2.24 \%$ \\
Chile & 1034 & $0.67 \%$ & Switzerland & 1912 & $1.25 \%$ \\
Mexico & 882 & $0.58 \%$ & Ireland & 1641 & $1.07 \%$ \\
Peru & 689 & $0.45 \%$ & Netherlands & 937 & $0.61 \%$ \\
French Guiana & 525 & $0.34 \%$ & Belgium and Lux. & 842 & $0.55 \%$ \\
Others & 2297 & $1.50 \%$ & Austria & 501 & $0.33 \%$ \\
& & & Others & 1308 & $0.85 \%$ \\
Pacific & 2907 & $1.90 \%$ & & & \\
Australia & 2069 & $1.35 \%$ & & & \\
New Zealand & 838 & $0.55 \%$ & & & \\
\hline Notes: & & & & \\
\hline
\end{tabular}

Notes: 1491 (1\%) individuals out of this table answered "unknown" for migration country.This table considers 24-64 year-old individuals that were born in the state where they answered the 2010 Brazilian census. The total is 153298 individuals.

Rich countries are the top destination places for returnee migrants. The U.S., Japan, Portugal, the U.K., Spain and Italy had been the choice for $70 \%$ of returnees. ${ }^{20}$

Table 2 shows the distribution of return migrants in Brazilian states. ${ }^{21}$ Returnees are over-represented in the most developed Brazilian regions: the Center-West has $9.54 \%$ of migrants, while the population's share is $7.37 \%$. The South has $24.89 \%$ of the returnees and $14.36 \%$ of the population. The Southeast has $53.81 \%$ of the returnees and $42.13 \%$ of the population.

\footnotetext{
${ }^{19}$ Which reduced the volume to 153298 individuals.

${ }^{20}$ For comparison, foreign migrants have more dispersed origins, but proximity seems to count more. Bolivia, Paraguay, Argentina, Peru and Uruguay were the origin of $39 \%$ of foreign immigrants in Brazil, from 2001 to 2010.

${ }^{21}$ See figure 5 in section Appendix A to locate each Brazilian region in a map.
} 
Table 2: State of Origin of Returnee Migrants

\begin{tabular}{lrrlrc}
\hline State & Returnees & Perc. & State & Returnees & Perc. \\
North & 4591 & $2,99 \%$ & Northeast 13440 & $8,77 \%$ & \\
Pará & 2008 & $1,31 \%$ & Bahia & 5119 & $3,34 \%$ \\
Rondônia & 890 & $0,58 \%$ & Pernambuco & 2983 & $1,95 \%$ \\
Amazonas & 760 & $0,50 \%$ & Ceará & 2224 & $1,45 \%$ \\
Amapá & 341 & $0,22 \%$ & Paraíba & 961 & $0,63 \%$ \\
Tocantins & 311 & $0,20 \%$ & Maranhão & 883 & $0,58 \%$ \\
Acre & 141 & $0,09 \%$ & Rio Grande do Norte & 470 & $0,31 \%$ \\
Roraima & 140 & $0,09 \%$ & Alagoas & 372 & $0,24 \%$ \\
Piauí & 295 & $0,19 \%$ & & & \\
Center-West & 14626 & $9,54 \%$ & Sergipe & 133 & $0,09 \%$ \\
Goiás & 8543 & $5,57 \%$ & & & \\
Mato Grosso do Sul & 3356 & $2,19 \%$ & Southeast & 23142 & $15,10 \%$ \\
Distrito Federal & 1631 & $1,06 \%$ & São Paulo - Metro & 22290 & $14,54 \%$ \\
Mato Grosso & 1096 & $0,71 \%$ & Minas Gerais & & \\
São Paulo - Rest & 21913 & $14,29 \%$ & & 11600 & $7,57 \%$ \\
South & 38150 & $24,89 \%$ & Rio de Janeiro & 3546 & $2,31 \%$ \\
Paraná & 22963 & $14,98 \%$ & Espírito Santo & & \\
Rio Grande do Sul & 8837 & $5,76 \%$ & & & \\
Santa Catarina & 6350 & $4,14 \%$ & & & \\
\hline
\end{tabular}

Notes: This table considers 24-64 year-old individuals that were born in the state where they answered the 2010 Brazilian census. The total is 153298 individuals.

Returnees are under-represented in the least developed regions: while the North has $2.99 \%$ of returnees, it accounts for $8.33 \%$ of the Brazilian population. The Northeast has $8.77 \%$ of returnees and $27.82 \%$ of the population.

Table 3 reports data on education level and gender of non-migrant natives and returnees. Individuals that migrated are over-represented in categories of higher education, as Tertiary Education and Secondary Education. Conversely, they are under-represented in the other lower education categories: Primary Education and No Education. The difference in the No Education category is striking: while $43.3 \%$ of natives are in this category, this is the case for only $16 \%$ of returnees. All in all, statistics on individuals' education suggest positive selection. In regards to gender, male returnees are over-represented compared to those non-migrant male individuals. The percentage of men is $48 \%$ in the native (non-immigrant) population, while this percentage is $53 \%$ in the returnee sample.

The measure of inequality used in the econometric analysis is based on the quintile ratio. ${ }^{22}$ Data on countries' inequality is obtained from the United Nations Development Programme - UNDP (2011). ${ }^{23}$ Brazilian states' quintile ratio is calculated using census 2010 data. The average differences of countries' quintile ratio and Brazilian states' quintile ratio are mostly negative. In $90 \%{ }^{24}$ of the cases that difference is negative, the average is -9.60 .

Figure 3 shows the k-density of the wages of non-migrants and returnees. Some locations ${ }^{25}$ were chosen due to their importance or specificity. Figure

\footnotetext{
${ }^{22}$ The quintile ratio is the proportion between the average income of the $20 \%$ richest individuals over the average income of the $20 \%$ poorest individuals

${ }^{23}$ Data is available at http : / / www . undp.org/content/undp/en/home/librarypage/ hdr/human_developmentreport2011.html

${ }^{24}$ Considering 638 pairs of Country-Brazilian State in the largest samples of estimations, those in table 4 .

${ }^{25}$ See figure 5 in section Appendix A to locate each Brazilian state in a map.
} 
Table 3: Education Level and Gender

\begin{tabular}{|c|c|c|c|c|c|c|}
\hline & \multicolumn{6}{|c|}{ Returnees } \\
\hline & \multicolumn{2}{|c|}{ Men } & \multicolumn{2}{|c|}{ Women } & \multicolumn{2}{|c|}{ Total } \\
\hline & Individuals & Perc. & Individuals & Perc. & Individuals & Perc. \\
\hline No Education & 14445 & $17,70 \%$ & 10066 & $14,00 \%$ & 24511 & $16,00 \%$ \\
\hline Primary & 11523 & $14,10 \%$ & 8155 & $11,40 \%$ & 19678 & $12,80 \%$ \\
\hline Secondary & 30079 & $36,90 \%$ & 25624 & $35,70 \%$ & 55703 & $36,30 \%$ \\
\hline Tertiary & 25276 & $31,00 \%$ & 27743 & $38,60 \%$ & 53019 & $34,60 \%$ \\
\hline \multirow[t]{4}{*}{ Unknown } & 190 & $0,20 \%$ & 197 & $0,30 \%$ & 387 & $0,30 \%$ \\
\hline & \multicolumn{6}{|c|}{ Natives (non-migrants) } \\
\hline & \multicolumn{2}{|c|}{ Men } & \multicolumn{2}{|c|}{ Women } & \multicolumn{2}{|c|}{ Total } \\
\hline & Ind. (000’s) & Perc. & Ind. (000's) & Perc. & Ind. (000's) & Perc. \\
\hline No Education & 16900 & $45,70 \%$ & 16300 & $41,10 \%$ & 33200 & $43,30 \%$ \\
\hline Primary & 5995 & $16,20 \%$ & 6138 & $15,50 \%$ & 12133 & $15,80 \%$ \\
\hline Secondary & 10200 & $27,60 \%$ & 11500 & $29,00 \%$ & 21700 & $28,30 \%$ \\
\hline Tertiary & 3793 & $10,30 \%$ & 5548 & $14,00 \%$ & 9341 & $12,20 \%$ \\
\hline Unknown & 112 & $0,30 \%$ & 135 & $0,30 \%$ & 247 & $0,30 \%$ \\
\hline
\end{tabular}

3 (a) refers to the metropolitan area of São Paulo ${ }^{26}$, the biggest state in the country, and figure 3 (b) refers to Rio de Janeiro, the second most important economy in Brazil. Figure 3 (c) shows the wage distribution for Distrito Federal, the location with the highest average wage and the most unequal location, while figure 3 (d) refers to Piauí, the state with the lowest average wage. Figure 3 (e) shows data for Santa Catarina, the state with the highest equality, and figure 3 (f) shows the distribution of wages in Pernambuco, the state presenting the highest average relative wages in the econometric analysis. ${ }^{27}$

One can notice in these figures that returnees are distributed at higher wages than non-migrants natives, which suggests positive selection. This is more evident for relatively poor states like Piauí and Pernambuco, and unequal locations like Distrito Federal than for large areas like São Paulo and Rio de Janeiro ${ }^{28}$. Remarkably, the most egalitarian state in Brazil, Santa Catarina, presents similar distribution of wages, when returnees and non-migrants are compared.

\section{Results}

\subsection{First-Step Estimations}

Equation (11) is regressed twice. First without demographic controls (vector $\mathbf{X}_{i}^{k}$ ) estimating unadjusted relative wages, and then with demographic controls estimating adjusted relative wages. While the former indicates selection on observed and unobserved characteristics of migrants, the latter indicates selection only on unobserved characteristics. We considered hourly wages for

\footnotetext{
${ }^{26}$ The state of São Paulo is broken down into two regions: the metropolitan area and the rest.

${ }^{27}$ The econometric section shows that returnee migrants residing in Pernambuco have Brazil's highest average wage, relative to natives. Figure 6 illustrates this finding.

${ }^{28}$ These regions are precisely the São Paulo metropolitan area and the state of Rio de Janeiro.
} 


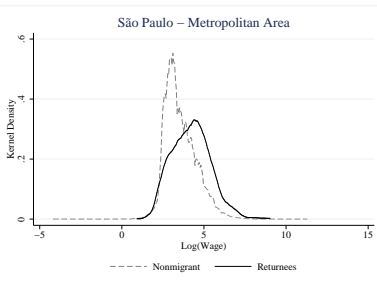

(a) São Paulo (Metropolitan Area) Wages' K-Density

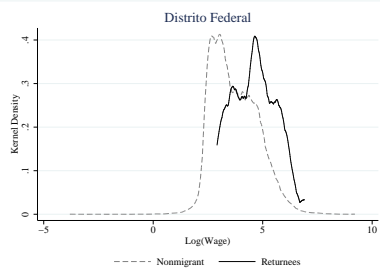

(c) Distrito Federal Wages' K-Density

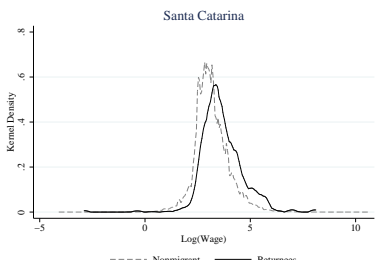

(e) Santa Catarina Wages' K-Density

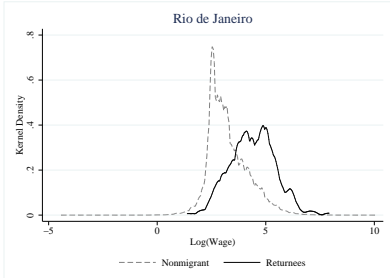

(b) Rio de Janeiro Wages' K-Density

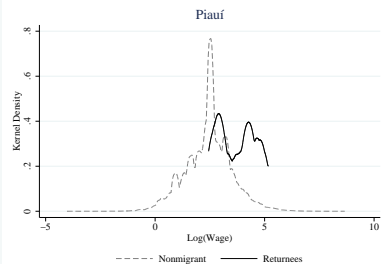

(d) Piauí Wages' K-Density

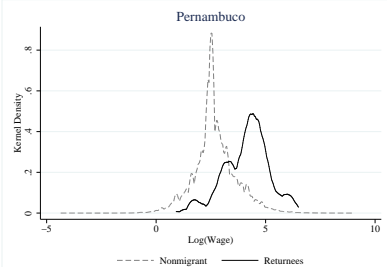

(f) Pernambuco Wages' K-Density

Figure 3: Wages K-Density

all estimations. ${ }^{29}$

Two sets of first-step regressions are estimated. The first set regresses equation (11) 28 times for unadjusted wages: for each Brazilian state and Distrito Federal. ${ }^{30}$ Each regression estimates the relative unadjusted wage $\left(\delta_{i j}\right)$ for an average of 11.39 countries, which comprises 638 observations (11.39 countries $\times 28$ states $\times 2$ cohorts $=638$ ) for the second step. Figure 4 shows the distribution of these relative wages, and table 4 reports the results from second-step estimations using them as a dependent variable.

The second set of regressions estimates equation (11) 28 times for adjusted wages, resulting in 638 values of adjusted $\delta_{i j}$. Figure 5 shows the distribution of these adjusted relative wages, and table 5 reports the results from secondstep estimations where they are the dependent variable.

We restricted the sample to male workers between 24 and 64 years who were born in the state they reside (where they answered the census). The gender restriction prevents any issue related to discrimination and mitigates bias due to tied migration. ${ }^{31}$ Estimations are made twice, for two cohorts: one for migrants that came back to Brazil before 2005 and another for those who arrived after 2006.

\footnotetext{
${ }^{29}$ Hourly wages are obtained dividing the individual monthly salary earned in the principal job by the quantity of hours worked.

${ }^{30}$ Brazil has 26 states, but the very large state of São Paulo is broken down into two regions: the metropolitan area and the rest.

${ }^{31}$ Tied migration occurs when the decision of migrating considers the wage difference of the family, and not the individual wage difference (Borjas and Bronars, 1991).
} 
We chose to regress at state level for two reasons. Firstly, we eliminated geographical heterogeneities that could impact wages or migration choice. In the sample studied, the average monthly wage in Distrito Federal is BRL2,545 (the highest in the country), while the average wage in Piauí is BRL545.00 (the lowest in the country). Amenities also differ between states. For instance, average annual temperatures vary from $18.1^{\circ}$ (in Santa Catarina) to $27.4^{\circ}$ (in Roraima). ${ }^{32}$

Secondly, we considered a returnee an individual that was born in a given Brazilian state and returned to the same state, even if their current city of residence is not their birthplace. By doing so, we did not discard from our analysis the individual that came back to Brazil and does not live exactly in the same city of birth, but on another city in the same state. In addition, we did not consider the sequential migrant.

Estimations of unadjusted $\delta_{i j}$ indicate that selection on observed and unobserved skills is primarily positive. Indeed, return migrants earn higher wages than nonmigrants in $80 \%$ of the observations. ${ }^{33}$ Figure 4 shows the distribution of log-wage differences, the average is $0.79 .{ }^{34}$

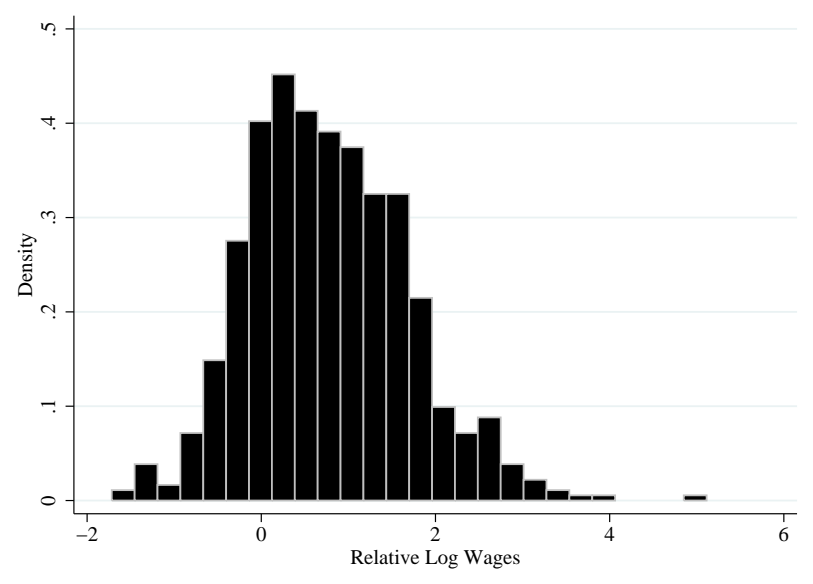

Figure 4: Histogram of Relative Log Wages

Estimations of adjusted relative wages indicate that selection on unobserved is also primarily positive. Return migrants earn higher adjusted wages than non-migrants in $68 \%$ of the observations. Figure 5 shows the distribution of wage differences. Relative adjusted wages present smaller values than those of unadjusted wages. As observable characteristics such as education and age are controlled, differences in migrants' wages relative to natives' are reduced. The average wage is 0.33 .

\footnotetext{
${ }^{32}$ Source: normaisClimatologicas

${ }^{33}$ Based on the table 4 sample with 638 observations, where each observation is a triplet statecountry-cohort.

${ }^{34}$ This finding does not verify the predictions of Assunção \& Carvalho (2013), who expect emigration of middle-class individuals from a country like Brazil, resulting in more equality on their return to the country. Instead we find that returnees are positively selected. The Gini index for the entire population is 0.52520 , while the Gini index for non-migrant natives alone is
} 


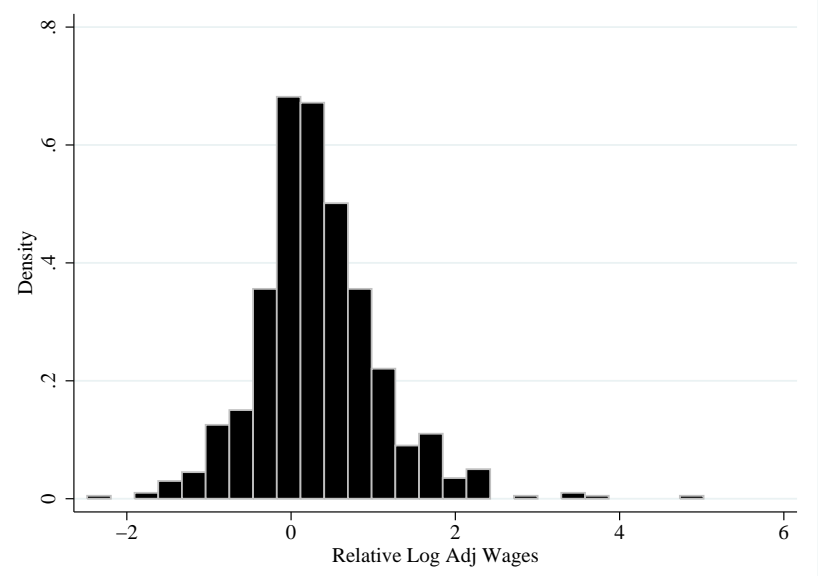

Figure 5: Histogram of Relative Log Adjusted Wages

Figure 6 shows the unadjusted relative average wage by Brazilian state . $^{35}$. The Northeast presents the highest wages, where returnees earn from $54 \%$ (in Sergipe) to $174 \%$ (in Alagoas) higher wages than natives. This region seems to receive the biggest benefits from return migration. Nevertheless, Table 2 indicates that returnees are under-represented in this region. One possible explanation is that positive self-selection is stricter in this region and only the very high-skilled individuals succeed in migrating. It is worth to note that these values are much larger than those found in Borjas \& Bronars (1991), which may reflect the higher inequality in Brazil compared to the US.

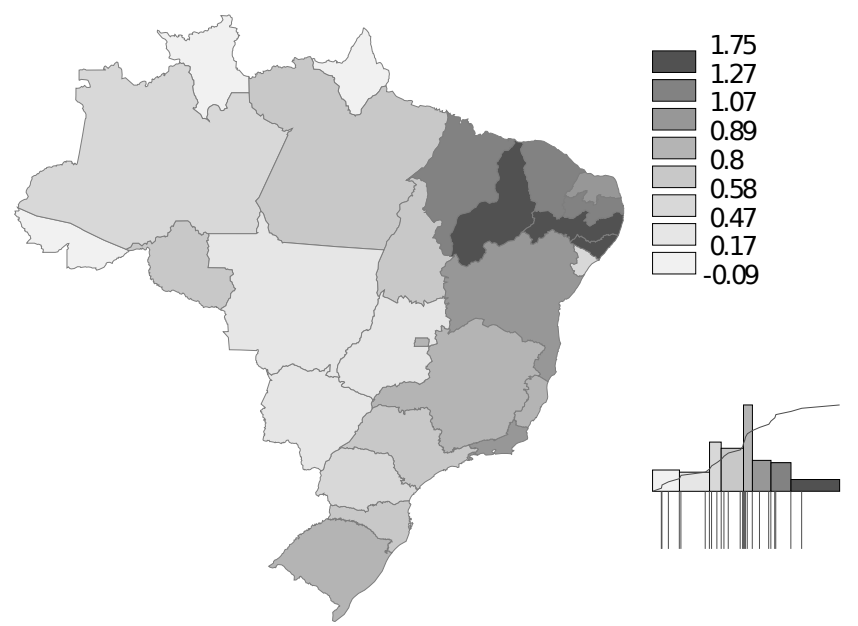

Figure 6: Average (by State) Immigrants' Relative Log Wages

Other Brazilian regions also receive a human capital increase, but to a

0.52455. The impact of return migration on inequality, if any, is positive.

${ }^{35}$ See figure 5 in section Appendix A to locate each state Brazilian in a map. 
lesser degree. On average, return migrants earn from $-9 \%$ (in Roraima) to $104 \%$ (in Rio de Janeiro) across states of these regions.

\subsection{Second-Step Estimations}

As the dependent variable is a coefficient estimated in the first step, residuals are heteroscedas-tic.In order to correct this, second-step estimations are obtained through a generalized least squares estimator. ${ }^{36}$

\section{Unadjusted Wages}

Table 4 shows the results for the estimable second-step equation (14) for unadjusted wages. Regression (1) estimates the returnee's relative wage on the inequalities' difference $q_{j}-q_{i}$ that indicates the difference of return to skills between country of migration and Brazilian state. This regression would test Borjas' specification $(1987,1991,1996)$, where time-equivalent costs do not depend on skills. However, contrarily to the model's prediction, the coefficient of $q_{j}-q_{i}$ is not positive and highly significant. As expected, the omission of migration time-equivalent costs may lead to a missing variable bias.

We estimated different specifications by taking into account migrations costs. Firstly, we considered in columns (2) and (3) that time-equivalent costs decrease with skills uniformly, in spite of differences in rates of return to skills across Brazilian states. Secondly, we considered that differences in rates of return to skills may imply differences to the extent to which time-equivalent costs decrease with skills: column (4) reports results for the complete equation (14).

Regression (2) estimates a positive effect of distance on migration selection, as predicted by the theoretical model. ${ }^{37}$ Brazilians that migrated to faroff countries had to pay a high cost of migration. Low-skilled individuals, regardless of the occasional possibility of higher wages, were less likely to be able to afford such costs as these amounts represented large proportions of these individuals' income.

Nonetheless, it is interesting to note that, although this result confirms the theory, the effect of distance on selection has an unexpected inverted Ushape. The maximum positive effect of distance is $5438 \mathrm{~km}$ (which roughly corresponds to Europe). The effects of distance decrease until the maximum value reached by distance in the sample is $11,702 \mathrm{~km}$.

Column (3) introduces other variables that are correlated to migration costs. Common language is a dummy variable that equals to one if Portuguese is one of the languages spoken in the migration country. Contiguity is a dummy variable that equals to one if the Brazilian state and the migration country have a common border. Both variables are negatively correlated with migration costs, which reduces the amount of expenses an immigrant has to pay. Therefore, these variables indicate a reduction in migration costs, allowing low-skilled individuals to migrate and contributes to a negative selection. Coefficients of both variables have, indeed, a negative sign, presenting a significant coefficient. The coefficient of $q_{j}-q_{i}$ still remains negative in regressions (2) and (3).

\footnotetext{
${ }^{36}$ See Borjas (1987) for details.

${ }^{37}$ The quadratic function of distance has roots 0 and 10.88 (thousands $\mathrm{km}$ ). The maximum value reached by distance is 11,702 thousands $\mathrm{km}$.
} 
Table 4: Results: Unadjusted wages

\begin{tabular}{|c|c|c|c|c|}
\hline $\begin{array}{l}\text { Dependent Variable: } \\
\Delta \text { of } \operatorname{Ln}\end{array}$ & (1) & (2) & (3) & (4) \\
\hline$q_{j}-q_{i}-0.017^{* * * *}$ & $\begin{array}{l}-0.014^{* * *} \\
-0.005\end{array}$ & $\begin{array}{l}-0.012^{* *} \\
-0.005\end{array}$ & $\begin{array}{l}0.013^{*} \\
-0.007\end{array}$ & \\
\hline Distance & & $0.174^{* * * *}$ & $0.128^{* *}$ & $-0.165^{* *}$ \\
\hline meters $* 10^{3}$ & & $-0,045$ & $-0,051$ & $-0,083$ \\
\hline Distance $^{2}$ & $\alpha_{3}$ & $-0.016^{* * *}$ & $-0.013^{* *}$ & $0.021^{* *}$ \\
\hline meters $* 10^{2} * 10^{6}$ & & -0.004 & -0.004 & -0.01 \\
\hline Common Language & $\alpha_{4}$ & & $\begin{array}{l}-0.237^{* *} \\
-0.12\end{array}$ & $\begin{array}{l}-0.969^{* *} \\
-0.44\end{array}$ \\
\hline Contiguity & $\alpha_{5}$ & & $\begin{array}{l}-0.557^{* * *} \\
-0.209\end{array}$ & $\begin{array}{l}-0.542 \\
-0.542\end{array}$ \\
\hline Distance $* q_{i}$ & $\alpha_{6}$ & & & $0.022^{* * *}$ \\
\hline Distance $^{2} * q_{i}$ & $\alpha_{7}$ & & & $\begin{array}{l}-0.005 \\
-0.002^{* * *} \\
-0,001\end{array}$ \\
\hline Common Language $* q_{i}$ & $\alpha_{8}$ & & & $\begin{array}{c}-0.03 \\
-0.022\end{array}$ \\
\hline Contiguity $* q_{i}$ & $\alpha_{9}$ & & & 0.004 \\
\hline Constant & $\begin{array}{l}0.668^{* * *} \\
-0,071\end{array}$ & $\begin{array}{l}0.332^{* * *} \\
-0,127\end{array}$ & $\begin{array}{l}0.543^{* * *} \\
-0,147\end{array}$ & $\begin{array}{l}0.439^{* * * *} \\
-0.146\end{array}$ \\
\hline Observations & 638 & 638 & 638 & 638 \\
\hline R-squared & 0 & 0.02 & 0.05 & 0.11 \\
\hline
\end{tabular}

In column (4) we allow for differences in the return to skill and establish differences in the correlation between time-equivalent costs and skills. We took all costs variables considered in column (3). The difference in return to skills between the Brazilian state and the country, $q_{j}-q_{i}$, presents the expected positive sign predicted by the theory (which confirms Roy's model) and it is significant at a $10 \%$ significance level.

Interestingly, one can note that the shape of the distance's effect on skill changes according to the location's inequality, but it is mostly strictly increasing as the range of $q_{i}$ varies from 11 to $39 .{ }^{38}$ This result helps to elucidate the apparent U-shape impact of distance on selection found in the previous regression. We can see that, once the heterogeneity of inequality across locations is considered, the impact of distance on migration selection is predominantly strictly increasing.

The theoretical predictions regarding migration costs given by equation 10 and estimated according to equation 15, are completely found only for distance in regression (4). The positive impact of distance on self-selection is accentuated by the inequality level of the origin place. Regarding other variables, only language presents a significant and negative coefficient in this specification, although contiguity presents the expected negative sign.

\section{Adjusted Wages}

Table 5 reports results for adjusted wages in equation (14). A vector of demographic characteristics is included in the regressions of the first step (equation

\footnotetext{
${ }^{38}$ The variable $q_{i}$ varies from 11 to 39 , with a mean equals to 18 . At the lowest limit of $q_{i}$, the impact of distance on selection is described by $0.077 \mathrm{Dist}-0.001 \mathrm{Dist}^{2}$, which is strictly increasing in the interval. At the mean (18), the impact is 0.23 Dist -0.015 Dist ${ }^{2}$, which is increasing until distance $=7.67$ (thousands $\mathrm{km}$ ), and includes $89.34 \%$ of the observations. Finally, at the highest limit of $q_{i}$, i.e. 39 , we have $73.67 \%$ of the observations included in the interval where the impact of distance on migration selection is increasing.
} 
Table 5: Results: Adjusted wages

\begin{tabular}{|c|c|c|c|c|}
\hline $\begin{array}{l}\text { Dependent Variable: } \\
\Delta \text { of Ln }\end{array}$ & (1) & (2) & (3) & (4) \\
\hline$q_{j}-q_{i}$ & $\begin{array}{l}-0.002 \\
-0.004\end{array}$ & $\begin{array}{c}0 \\
-0.004\end{array}$ & $\begin{array}{l}0.001 \\
-0.004\end{array}$ & $\begin{array}{l}0.012^{* *} \\
-0.006\end{array}$ \\
\hline Distance & $\alpha_{2}$ & $0.097^{* * *}$ & $0.081^{*}$ & -0.023 \\
\hline meters $* 10^{3}$ & & -0.037 & -0.042 & -0.07 \\
\hline Distance $^{2}$ & $\alpha_{3}$ & $-0.009^{* * *}$ & $-0.008^{* *}$ & 0.004 \\
\hline meters $* 10^{2} * 10^{6}$ & & -0.003 & -0.003 & -0.008 \\
\hline Common Language & $\alpha_{4}$ & & -0.082 & $\begin{array}{l}-0.746^{* *} \\
-0.373\end{array}$ \\
\hline Contiguity & $\alpha_{5}$ & & $\begin{array}{l}-0.197 \\
-0.175\end{array}$ & $\begin{array}{c}-0.332 \\
-0.46\end{array}$ \\
\hline Distance $* q_{i}$ & $\alpha_{6}$ & & & $\begin{array}{l}0.008^{* *} \\
-0.004\end{array}$ \\
\hline Distance $^{2} * q_{i}$ & $\alpha_{7}$ & & & $-0.001^{*}$ \\
\hline Common Language $* q_{i}$ & $\alpha_{8}$ & & & $\begin{array}{l}0.031^{*} \\
-0.019\end{array}$ \\
\hline Contiguity $* q_{i}$ & $\alpha_{9}$ & & & $\begin{array}{r}0.009 \\
-0.023\end{array}$ \\
\hline Constant & $0.317^{* * *}$ & 0.118 & 0.193 & 0.149 \\
\hline Observations & $\begin{array}{c}-0.059 \\
638\end{array}$ & $\begin{array}{c}-0.105 \\
638\end{array}$ & $\begin{array}{c}-0.123 \\
638\end{array}$ & $\begin{array}{c}-0.124 \\
638\end{array}$ \\
\hline R-squared & 0 & 0.01 & 0.02 & 0.03 \\
\hline
\end{tabular}

11). In line with Borjas \& Bratsberg (1996), these characteristics are: age, age squared, education level, marital status, health and metropolitan residence.

Regression (1) estimates the returnee's relative adjusted wage on the inequalities' difference $q_{j}-q_{i}$ that indicates the difference of return to skills between country of migration and Brazilian state. Unlike the results for unadjusted wages, $q_{j}-q_{i}$ does not present a negative and significant coefficient in any specification.

Columns (2) and (3) introduce variables that capture migration costs, namely, distance, common language and contiguity. Only distance presents a positive and significant impact on selection. ${ }^{39}$

Similarly to estimations of unadjusted wages, regression (4) also confirms theoretical predictions for non-observable characteristics. Inequality differences have a positive and significant coefficient, indicating that individuals migrate to the place where their (non-observable) characteristics are valued the most. Concerning time-equivalent costs, they are significant only when interacting with the inequality ratio $q_{i}$.

Theoretical predictions given by equation 10 and estimated according to equation 15 are completely found only for distance, in column (4). It is surprising that Common Language presents a positive and significant coefficient, because the theoretical prediction is a positive coefficient.

Self-selection is, therefore, driven by migration costs and return to skills, both observable and non-observable. More productive Brazilians migrate to the countries that value workers' high productivity the most.

\footnotetext{
${ }^{39}$ The quadratic function of distance has roots 0 and 10.13 (thousands $\mathrm{km}$ )in regression (3). The maximum value reached by distance is 11.702 thousands $\mathrm{km}$.
} 


\section{Conclusion}

This paper analyzes the self-selection of returnee migrants in Brazil from 2001 to 2010. As we compare the wages of returnees to those of non-migrant natives, the observed selection occurred when these individuals migrated from Brazil to a foreign country. Primarily positive selection is estimated using individual data from the 2010 census.

This selection is explained by time-equivalent migration costs and inequality. Time-equivalent costs are higher for low-skilled individuals, as they spend a longer period of time than high skilled individuals to amass the same income. This period is still longer if the inequality is high. Alternatively, one can think that low-skilled individuals face more difficulties with bureaucratic requirements than high-skilled individuals. Yet, credit constraints may raise migration costs for low-income individuals.

We find empiric evidence supporting the role of the correlation between migration costs and skills determining positive selection. This selection is accentuated in Brazilian locations with high inequality and high rates of return to skill, as the correlation is higher.

The empiric analysis also confirms the predictions of Borjas (1987). Lowskilled individuals have incentives to emigrate from Brazilian states with relative (to destination country) high inequality and high returns to skills, implying a negative impact on selection. This impact is only verified once the interaction between migration costs and inequality is controlled. In spite of this partial negative effect on selection, migrations costs mechanisms prevail, resulting in positive selection.

In Brazil, locations with high levels of inequality are the ones that suffer the most with the brain drain. Consequently, they are the most benefited with the increase of human capital when those emigrants returns.

\section{Acknowledgements}

We would like to acknowledge the helpful comments by Izete Pengo Bagolin, Paulo Jacinto, Ely José de Mattos, Tobias Müller, Sabino Porto. We are grateful to Philippe Waniez for the mapping software Philcarto.

\section{Bibliography}

Assunção, J. \& Carvalho, F. (2013), 'Financial constraints, endogenous educational choices and self-selection of migrants', Brazilian Review of Econometrics 33(2), 99-122.

Belot, M. V. K. \& Hatton, T. J. (2012), 'Immigrant selection in the oecd', The Scandinavian Journal of Economics 114(4), 1105-1128.

Borjas, G. J. (1987), 'Self-selection and the earnings of immigrants', The American Economic Review 77(4), 531-553.

Borjas, G. J. \& Bratsberg, B. (1996), 'Who leaves? the outmigration of the foreign-born', The Review of Economics and Statistics 78(1), 165-176.

Borjas, G. J. \& Bronars, S. G. (1991), 'Immigration and the Family', Journal of Labor Economics 9(2), 123-48. 
Chiquiar, D. \& Hanson, G. H. (2005), 'International Migration, Self-Selection, and the Distribution of Wages: Evidence from Mexico and the United States', Journal of Political Economy 113(2), 239-281.

Chiswick, B. R. (1999), 'Are immigrants favorably self-selected?', The American Economic Review 89(2), 181-185.

Docquier, F. \& Rapoport, H. (2012), 'Globalization, brain drain, and development', Journal of Economic Literature 3(50), 681-730.

Facchini, G. \& Mayda, A. M. (2009), 'Does the welfare state affect individual attitudes toward immigrants? evidence across countries', Review of Economics and Statistics 2(91), 295-314.

Mankiw, N. G., Romer, D. \& Weil, D. N. (1992), 'A contribution to the empirics of economic growth', The Quarterly Journal of Economics 107(2), 407-437.

Müller, T. \& Tai, S. H. T. (2016), Individual attitudes towards migration: reconciling opposing views, Working paper series WPS 16-02-1, University of Geneva.

URL: Available at: http://www.unige.ch/ses/dsec/repec/files/16021.pdf

Romer, P. M. (1990), 'Endogenous Technological Change', Journal of Political Economy 98(5), S71-102.

Roy, A. D. (1951), 'Some thoughts on the distribution of earnings', Oxford Economic Papers 3(2), 135-146.

UNDP (2011), Human develpment report 2011, susteinability and equity: a better future for all, Technical report, United Nations Development Programme, New York.

\section{Appendix A}




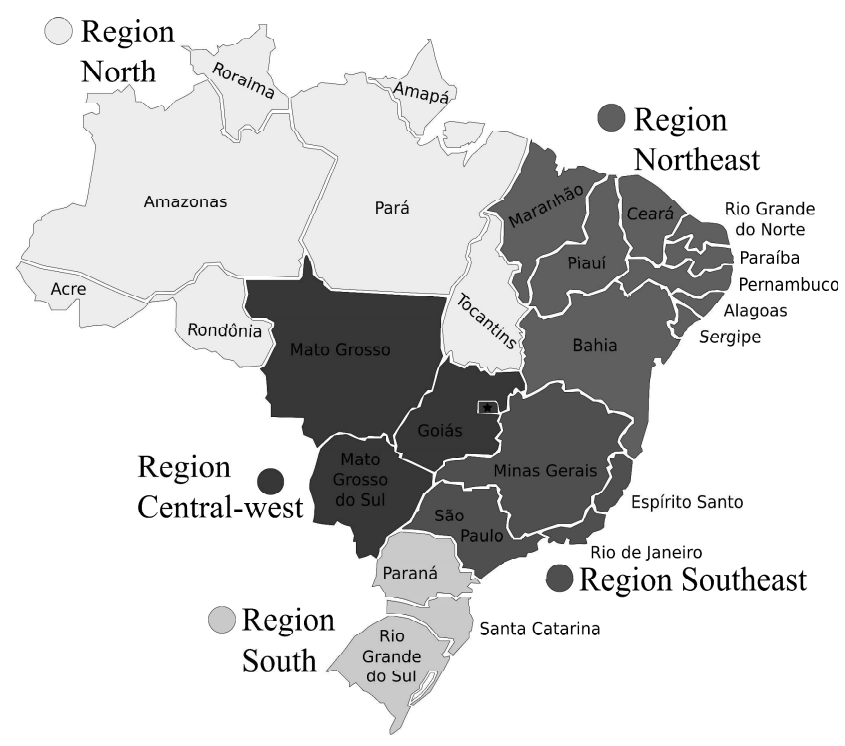

Figure A.1: Brazilian States and Regions 